\title{
CAPítTULO 5
}

\section{TECIDO ÓSSEO}

Lucimara Pereira Lorente

Geovana Raminelli

Douglas Fernandes da Silva

O tecido ósseo é um tipo especializado de tecido conjuntivo formado por células e material extracelular calcificado (matriz óssea). Esse tecido atua como suporte para os tecidos moles e protege órgãos vitais, sendo também o componente principal do esqueleto. Além disso, o órgão osso, que é composto por diferentes tipos de tecidos, dentre eles o tecido ósseo, funciona como depósito de cálcio, fosfato e outros íons, sendo que estes são armazenados ou liberados de maneira controlada para que se mantenham constantes as suas concentrações nos líquidos corporais. Esse órgão pode, também, absorver toxinas e metais pesados, diminuindo seus efeitos adversos em outros tecidos.

As células que fazem parte do tecido ósseo são:

- Osteócitos: células encontradas em cavidades ou lacunas no interior da matriz.

- Osteoblastos: células encontradas na periferia que sintetizam a parte orgânica da matriz.

- Osteoclastos: células gigantes, móveis e multinucleadas que reabsorvem o tecido ósseo, sendo envolvidos na remodelação dos ossos. 
A nutrição dos osteócitos depende de canalículos que existem na matriz, pois esta é uma matriz calcificada e, com isso, não existe difusão de substâncias através dela. Os canalículos possibilitam trocas de moléculas e íons entre os capilares sanguíneos e os osteócitos.

Todos os ossos são revestidos em suas superfícies por membranas conjuntivas que contêm células osteogênicas: o periósteo, que reveste as superfícies externas, e o endósteo, que reveste as superfícies internas.

\section{CÉlULAS DO TECIDO ÓSSEO}

Osteócitos: são células achatadas, com pequena quantidade de retículo endoplasmático granuloso, complexo de Golgi pouco desenvolvido e núcleo com cromatina condensada. Entretanto, mesmo que essas características indiquem diminuída atividade sintética, os osteócitos são essenciais para a manutenção da matriz óssea. Essas células são encontradas no interior da matriz óssea, ocupando as lacunas das quais partem canalículos - lembrando que cada lacuna contém apenas um osteócito.

Dentro dos canalículos, os prolongamentos dos osteócitos determinam, por meio de junções comunicantes, por onde podem passar pequenas moléculas e íons de uma célula para outra.

Osteoblastos: células que sintetizam a parte orgânica da matriz óssea, como o colágeno tipo I, proteoglicanos e glicoproteínas. Também sintetizam osteonectina, que facilita a deposição de cálcio, e osteocalcina, que estimula a atividade dos osteoblastos. Parte da osteocalcina produzida é transportada pelo sangue, que, por isso, atua tanto nos osteoblastos locais como nos distantes. Possuem a capacidade de concentrar fosfato de cálcio, participando da mineralização da matriz. Quando em intensa atividade sintética, são cuboides, com citoplasma muito basófilo, mas em estado pouco ativo se apresentam achatadas e a basofilia citoplasmática diminui.

Assim que o osteoblasto é aprisionado pela matriz recém-sintetizada, passa a ser chamado de osteócito. A matriz se deposita ao redor do corpo da célula e de seus prolongamentos, formando as lacunas e os canalículos. A matriz óssea recém-formada, próxima aos osteoblastos ativos e que ainda não está calcificada, é denominada de osteoide. 
Osteoclastos: são células móveis, gigantes, multinucleadas e ramificadas. Essas ramificações são muito irregulares, com forma e espessura variáveis. Frequentemente, nas áreas de reabsorção de tecido ósseo encontram-se porções dilatadas dos osteoclastos, colocadas em depressões da matriz escavadas pela atividade dessas células, chamadas lacunas de Howship.

Apresentam citoplasma granuloso, podendo apresentar vacúolos fracamente basófilos nos osteoclastos jovens e acidófilos nos osteoclastos maduros. Essas células se originam de precursores mononucleados provenientes da medula óssea que, quando em contato com o tecido ósseo, unem-se para formar os osteoclastos multinucleados.

\section{MATRIZ ÓSSEA}

A parte inorgânica da matriz óssea representa certa de $50 \%$ de seu peso. Nela, os íons mais encontrados são o fosfato e o cálcio. Nesse local, também são encontrados em pequenas quantidades magnésio, bicarbonato, potássio, sódio e citrato. Os cristais que se formam pelo cálcio e pelo fósforo têm a estrutura da hidroxiapatita $\left(\mathrm{Ca}_{10}\left(\mathrm{PO}_{4}\right)_{6}(\mathrm{OH})_{2}\right)$; os íons da superfície desses cristais são hidratados e, dessa forma, forma-se uma camada de água e íons em volta dos cristais. Essa camada recebe o nome de capa de hidratação e facilita a troca de íons entre o cristal e o líquido intersticial.

A parte orgânica da matriz é formada por fibras colágenas (95\%) compostas de colágeno do tipo I e por pequena quantidade de proteoglicanos e glicoproteínas. Os tecidos ricos em colágeno tipo I, mas que não contêm glicoproteínas, geralmente não se calcificam, podendo haver a participação desse componente na mineralização das matrizes dos ossos, onde as glicoproteínas estão presentes com maior relevância.

A combinação de fibras colágenas e hidroxiapatita é responsável pela rigidez e resistência do tecido ósseo.

\section{PERIÓSTEO E ENDÓSTEO}

As superfícies internas e externas dos ossos são revestidas por células osteogênicas e tecido conjuntivo, sendo o endósteo o que recobre a superfície interna, e o periósteo, a superfície externa.

A camada mais superficial do periósteo apresenta principalmente fibras colágenas e fibroblastos. Os feixes de fibras colágenas do periósteo que penetram o 
tecido ósseo e prendem firmemente o periósteo ao osso são denominadas fibras de Sharpey.

\section{TIPOS DE TECIDO ÓSSEO}

O osso é formado por parte sem cavidades visíveis, o osso compacto, e partes com muitas cavidades intercomunicantes, o osso esponjoso.

A calcificação que ocorre é macroscópica, e não histológica, pois o tecido compacto e os tabiques que separam as cavidades do osso esponjoso têm basicamente a mesma estrutura histológica.

Em ossos longos, as extremidades (epífises) são formadas por osso esponjoso com uma fina camada superficial compacta. A parte cilíndrica (diáfise) é quase totalmente compacta, com pequena quantidade de osso esponjoso na sua parte profunda, delimitando o canal medular. O osso compacto, principalmente nos ossos longos, é também chamado de osso cortical.

Os ossos curtos possuem o centro esponjoso, sendo recobertos em toda a sua periferia por uma camada compacta. Nos ossos chatos, que formam a abóbada craniana, existem duas camadas de osso compacto, as tábuas internas e externa, separadas por osso esponjoso que, nessa localização, recebe o nome de díploe.

A medula óssea ocupa as cavidades do osso esponjoso e o canal medular da diáfise dos ossos longos. No recém-nascido, toda a medula óssea tem cor vermelha, por causa do alto teor de hemácias, e é ativa na produção de células do sangue (medula óssea hematógena). Com a idade, vai sendo infiltrada por tecido adiposo, com diminuição da atividade hematógena (medula óssea amarela).

Existem dois tipos de tecido ósseo:

- Tecido ósseo imaturo ou primário.

- Tecido ósseo maduro, secundário ou lamelar.

Ambos contêm as mesmas células e os mesmo constituintes da matriz.

O tecido primário é aquele que aparece primeiro, tanto no desenvolvimento embrionário como na reparação das fraturas, sendo temporário e substituído por tecido secundário. Nele, as fibras colágenas se dispõem irregularmente, sem orientação definida; entretanto, no tecido ósseo secundário ou lamelar essas fibras se organizam em lamelas, com uma disposição muito peculiar. 
Tecido ósseo primário ou imaturo: é o primeiro tecido ósseo que aparece em cada osso (não lamelar), sendo substituído gradativamente por tecido ósseo lamelar ou secundário. É encontrado com menor frequência no adulto, persistindo apenas:

- Próximo às suturas dos ossos do crânio.

- Nos alvéolos dentários.

- Em alguns pontos de inserção de tendões.

Apresenta fibras colágenas dispostas em várias direções sem orientação definida, possui menos quantidade de minerais e maiores proporções de osteócitos.

Tecido ósseo secundário ou maduro: esse tecido, também chamado de lamelar, é geralmente encontrado no adulto. Tem como principal característica conter fibras colágenas organizadas em lamelas de 3 a $7 \mu \mathrm{m}$ de espessura, que ficam paralelas umas às outras ou se dispõem em camadas concêntricas em torno de canais com vasos, formando os sistemas de Havers ou ósteons.

As lacunas que contêm osteócitos estão normalmente situadas entre as lamelas ósseas, porém algumas vezes estão dentro delas. Em cada lamela, as fibras colágenas são paralelas umas às outras. Separando grupos de lamelas, ocorre frequentemente o acúmulo de uma substância cimentante, que consiste em matriz mineralizada, mas com baixa quantidade de colágeno.

$\mathrm{Na}$ diáfise dos ossos, as lamelas ósseas se organizam em arranjo típico, constituindo os sistemas de Havers, os circunferenciais interno e externo e os intermediários. O tecido ósseo secundário, que apresenta sistemas de Havers, é característico da diáfise dos ossos longos, embora estes também sejam encontrados no osso compacto de outros locais.

O sistema de havers (ósteon) é um cilindro longo, paralelo à diáfise e formado por quatro a vinte lamelas ósseas concêntricas. No centro do cilindro ósseo há um canal revestido de endósteo, o canal de havers, que contém vasos e nervos.

Os canais se comunicam entre si, com cavidade medular e com a superfície externa de osso por meio de canais transversais ou oblíquos chamados de canais de Volkmann. Estes se diferenciam dos canais de Havers porque não apresentam lamelas ósseas concêntricas. Todos os canais vasculares que existem no tecido ósseo surgem quando a matriz óssea se forma ao redor dos vasos preexistentes. 


\section{Lâmina: osso compacto descalcificado}

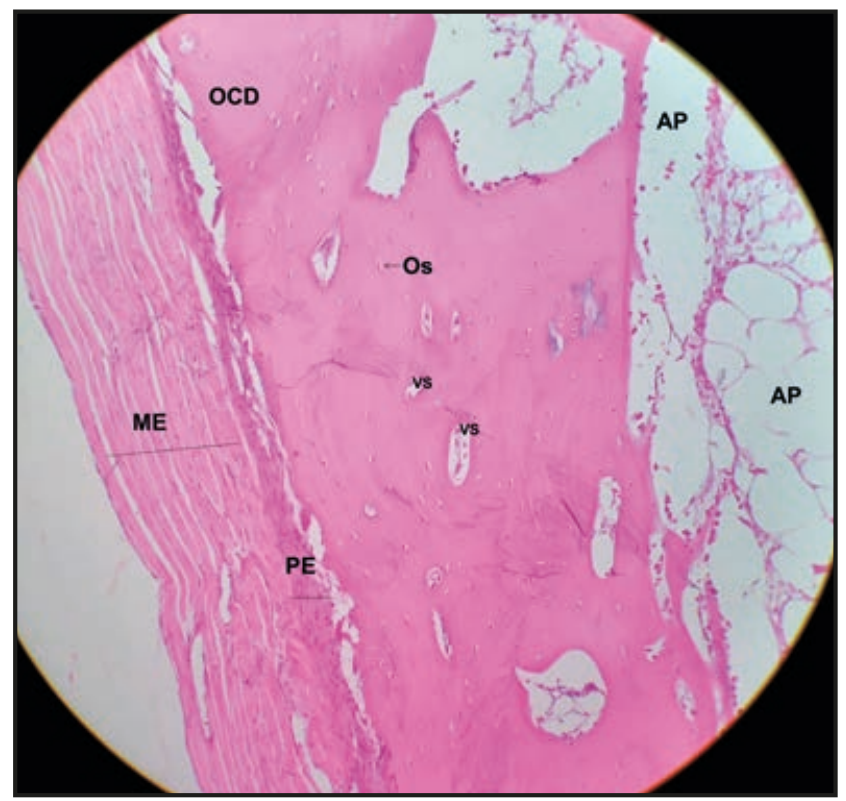

Figura 31 - Osso compacto descalcificado. ME: músculo esquelético;

PE: periósteo, OCD: osso compacto descalcificado; OS: ósteon, VS: vaso sanguíneo, AP: adipócitos. Ampliação: 100x. (HE).

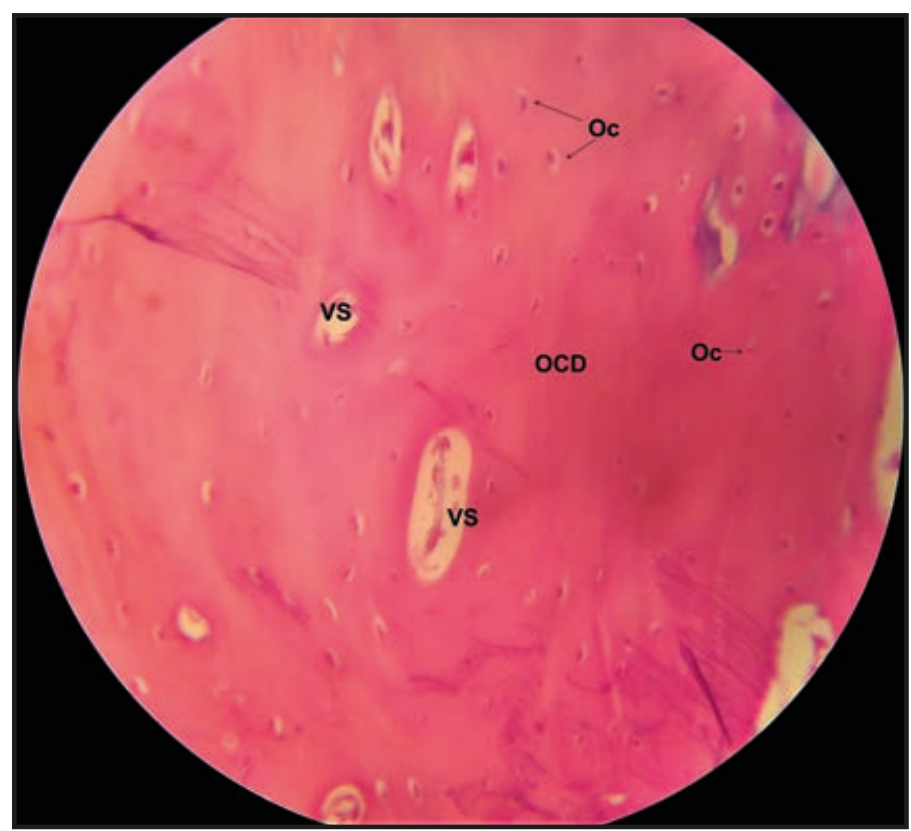

Figura 32 - Osso compacto descalcificado. OCD: osso compacto descalcificado;

Os: ósteon, Oc: osteócito; VS: vaso sanguíneo. Ampliação: 400x. (HE). 


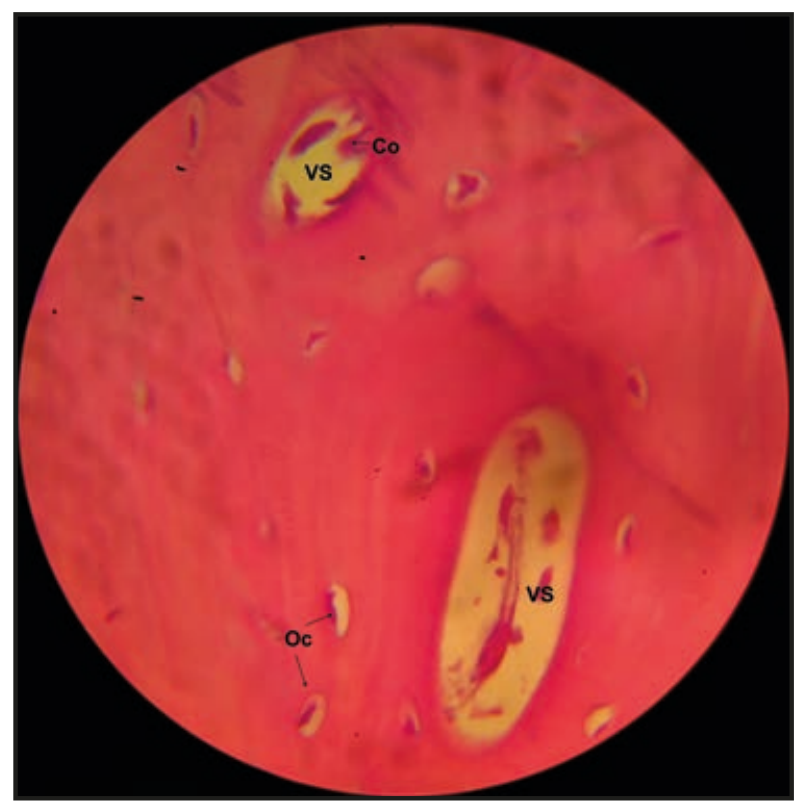

Figura 33 - Osso compacto descalcificado. Oc: osteócito; Co: célula osteogênica, VS: vaso sanguíneo. Ampliação: 1.000x. (HE).

Secção transversal de osso descalcificado humano, ósteon ou sistema de canais de Havers, os quais são circundados por várias lamelas de osso (não visíveis nas imagens). Os canais apresentam um pequeno vaso sanguíneo imerso em uma delgada camada de tecido conjuntivo e são revestidos por osteoblastos achatados e por células osteogênicas. Os osteócitos ocupam espaços conhecido como lacunas, as quais são revestidas por matriz osteoide não calcificada. 
